\title{
Insulin-stimulated phosphorylation of calmodulin
}

\author{
David B. SACKS, ${ }^{*} \|$ Harold W. DAVIS, $\dagger$ Dan L. CRIMMINS $\ddagger$ and Jay M. McDONALD $\S$ \\ *Department of Pathology, Brigham and Women's Hospital and Harvard Medical School, Boston, MA 02115, U.S.A., \\ †Department of Medicine, Indiana University School of Medicine, Indianapolis, IN 46202, U.S.A., \\ †Howard Hughes Medical Institute, Washington University School of Medicine, St. Louis, MO 63110, U.S.A., \\ and §Department of Pathology, University of Alabama at Birmingham, Birmingham, AL 35294, U.S.A.
}

\begin{abstract}
Calmodulin is phosphorylated in vitro by the insulin-receptor tyrosine kinase and a variety of serine/threonine kinases. Here we report that insulin stimulates the phosphorylation of calmodulin on average 3-fold in intact rat hepatocytes. Although calmodulin is constitutively phosphorylated, insulin increases phosphate incorporation into serine, threonine and tyrosine residues. We demonstrate that casein kinase II, an insulin-sensitive kinase, phosphorylates calmodulin in vitro on serine/thronine residues (Thr-79, Ser-81, Ser-101 and Thr-117). The ability of the insulin receptor to phosphorylate calmodulin that has been pre-phosphorylated by casein kinase II is enhanced up to 35-fold, and the sites of phosphorylation on calmodulin are shifted from tyrosine to threonine and serine. These observations, obtained with a new specific monoclonal antibody to calmodulin, confirm that insulin stimulates calmodulin phosphorylation in intact cells. The observation that calmodulin is phosphorylated in vivo, coupled with the recent demonstration that phosphocalmodulin exhibits altered biological activity, strongly suggests that phosphorylation of calmodulin is a critical component of intracellular signalling.
\end{abstract}

\section{INTRODUCTION}

Calmodulin, a $17 \mathrm{kDa} \mathrm{Ca}{ }^{2+}$-binding protein present in all eukaryotic cells, plays a key role in the regulation of a number of essential enzymes (for reviews, see [1,2]). It is not known how calmodulin activates enzymes differentially, but posttranslational modification of the molecule (e.g. phosphorylation) may represent a biologically important step in the regulation of calmodulin function. Phosphocalmodulin has been detected in chicken brain and muscle [3] and rat brain [4]. In addition, calmodulin has been reported to be phosphorylated in vitro by the insulin-receptor tyrosine kinase [5-7] and a variety of serine/threonine kinases $[3,4,8]$, and in intact cells apparently by a variety of kinases $[3,4,9,10]$. Despite these data, Blackshear \& Haupt [11] have reported that in 3T3-L1 fibroblasts, adipocytes and hepatocytes the phosphorylation of calmodulin is minimal and is not stimulated by insulin. However, the differences in methodology among the studies with intact cells preclude direct comparison.

Casein kinase II is a multipotential serine/threonine kinase consisting of an $\alpha \alpha^{\prime} \beta_{2}$ or $\alpha_{2} \beta_{2}$ structure with the $\alpha$ subunits $37-43 \mathrm{kDa}$ and $\beta$ subunits $24-27 \mathrm{kDa}$ (for review, see [12]). A variety of proteins in the cytosol, nucleus and membranes have been identified as substrates for casein kinase II in vitro and in vivo [12]. Phosphorylation of substrates by casein kinase II may affect substrate function directly. In some cases, however, phosphorylation has no direct effect on activity, but potentiates phosphorylation by other protein kinases, resulting in alterations in activity, e.g. protein phosphatase $1[12,13]$. Casein kinase II may be involved in insulin action as insulin increases its activity in 3T3-L1 mouse adipocytes, rat hepatoma cells [14], 3T3 fibroblasts [15] and adipocytes [16]. In addition, casein kinase II has been reported to phosphorylate the $\beta$-subunit of the insulin receptor [17].

In this paper we show that insulin stimulates the phosphorylation of calmodulin in intact rat hepatocytes on serine, threonine and tyrosine residues. Furthermore, we demonstrate, in a phosphorylation system in vitro, the ability of sequential kinase activation by casein kinase II and the insulin receptor to enhance the resulting phosphorylation of calmodulin, rendering the insulin-induced kinase activity entirely serine- and threonine-specific.

\section{EXPERIMENTAL}

\section{Materials}

Reagents were obtained as follows: radionuclides from Amersham (Arlington Heights, IL, U.S.A.); L-1-tosylphenylalanylchloromethane-treated trypsin from Worthington Biochemicals (Freehold, NJ, U.S.A.); poly(vinylidene difluoride) (ImmobilonP) from Millipore (Bedford, MA, U.S.A.); anti-phosphotyrosine IgG from Upstate Biotechnology Inc. (Lake Placid, NY, U.S.A.); and $\mathrm{Ca}^{2+}$-free pig brain calmodulin from Ocean Biologics (Edmond, WA, U.S.A.). H.p.l.c. columns were acquired from the suppliers as listed: Partisil 10-SAX from Whatman (Clifton, NJ, U.S.A.); Brownlee $\mathrm{C}_{18}$-PTC from ABI (Foster City, CA, U.S.A.); RPC $_{4}$ Vydac and Vydac 3040L oligonucleotide from the Nest Group (Southborough, MA, U.S.A.). All other chemicals were of reagent grade.

\section{Intact-cell phosphorylation assays}

Hepatocytes were isolated from rats by a modification [18] of the method of Berry \& Friend [19], washed with modified Krebs-Ringer buffer (120 mM- NaCl, $5 \mathrm{~mm}-\mathrm{KCl}, 1.25 \mathrm{~mm}-\mathrm{CaCl}_{2}$,

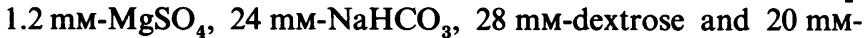
Hepes, pH 7.4) (buffer A) and incubated in this buffer for $30 \mathrm{~min}$ at $37^{\circ} \mathrm{C}$. Cells were gassed continuously with $\mathrm{O}_{2} / \mathrm{CO}_{2}(19: 1)$ during this incubation. After two washes with buffer $\mathrm{A}$, approx. $1 \times 10^{7}$ cells were incubated with $0.4 \mathrm{mCi}$ of $\left.{ }^{32} \mathrm{P}\right] \mathrm{P}_{1}$ in buffer $\mathrm{A}$ at $37^{\circ} \mathrm{C}$ for $60 \mathrm{~min}$, followed by incubation for $10 \mathrm{~min}$ at $37^{\circ} \mathrm{C}$ in the absence or presence of $67 \mathrm{nM}$-insulin. We confirmed that under these conditions ${ }^{32} \mathrm{P}$ uptake has reached steady state at $60 \mathrm{~min}$. The reaction was stopped with $10 \%(\mathrm{w} / \mathrm{v})$ trichloroacetic acid; equal amounts of protein were loaded onto each lane and separated by SDS/PAGE. After transfer to poly(vinylidene difluoride) $(75 \mathrm{~min}$ at $250 \mathrm{~mA})$, proteins were fixed with $0.2 \%$

\| To whom correspondence should be addressed. 
(v/v) glutaraldehyde [20,21], autoradiography was performed and the blot was probed with a specific anti-calmodulin monoclonal antibody [20].

For immunoprecipitation studies, the reaction was stopped by boiling SDS. This method yielded phosphorylation patterns identical with those observed with trichloroacetic acid termination. The samples were then placed on ice for $60 \mathrm{~min}$ and the SDS was removed by centrifugation $(678000 \mathrm{~g}$-min). Immunoprecipitation was performed by incubating the samples for $3 \mathrm{~h}$ at $4{ }^{\circ} \mathrm{C}$ with the anti-calmodulin monoclonal antibody crosslinked to Affi-Gel. The beads were washed twice with $50 \mathrm{~mm}$ Tris/ $\mathrm{HCl}(\mathrm{pH} 7.5) / 140 \mathrm{~mm}-\mathrm{NaCl} / 1 \%$ (v/v) Triton $\mathrm{X}-100$ and twice with $50 \mathrm{~mm}$-Tris $/ \mathrm{HCl}(\mathrm{pH} 7.5) / 140 \mathrm{~mm}-\mathrm{NaCl}$, boiled in solubilization buffer for $5 \mathrm{~min}$ and processed by SDS/PAGE, autoradiography and immunoblotting with anti-calmodulin or anti-phosphotyrosine antibodies. The specificity of the antiphosphotyrosine antibody was demonstrated by displacement with $50 \mathrm{~mm}-O$-phospho-L-tyrosine.

\section{Protein phosphorylation in vitro}

Standard phosphorylation assays were performed by preincubating $4.3 \mu \mathrm{M}$-calmodulin in a reaction mixture containing $50 \mathrm{~mm}$-Tris/ $\mathrm{HCl}$ (pH 7.2), $10 \mathrm{~mm}-\mathrm{MgCl}_{2}, 140 \mathrm{mM}-\mathrm{KCl}, 50 \mu \mathrm{M}-$ $\left[\gamma^{32} \mathrm{P}\right] \mathrm{ATP} \quad(5-10 \mu \mathrm{Ci}), \quad 0.86 \mu \mathrm{M}$-poly-(L-lysine) $\quad(30-70 \mathrm{kDa}$; mean $41 \mathrm{kDa}$ ), $1 \mathrm{~mm}-\mathrm{EGTA}$ and $0.4 \mathrm{mM}^{-\mathrm{CaCl}_{2}}$ (free $\mathrm{Ca}^{2+}$ concn. of $0.5 \mu \mathrm{M})$ in a final volume of $70 \mu \mathrm{l}$. After $10 \mathrm{~min}$ at $30^{\circ} \mathrm{C}$ the reaction was initiated by addition of 125-275 enzyme units ( 1 unit is the amount of enzyme that catalyses the incorporation of $1 \mathrm{pmol}$ of ${ }^{32} \mathrm{P}$ into casein $/ \mathrm{min}$ at $30^{\circ} \mathrm{C}$ ) of casein kinase II, purified from rabbit reticulocytes [22]. The reaction was terminated after $30 \mathrm{~min}$ at $30^{\circ} \mathrm{C}$ with $10 \%$ trichloroacetic acid at $4{ }^{\circ} \mathrm{C}$, followed immediately by addition of $10 \mu \mathrm{l}$ of $0.1 \%$ BSA. The samples were solubilized and processed by SDS/PAGE and autoradiography as described [6].

When calmodulin was phosphorylated initially by casein kinase II and subsequently by the insulin-receptor kinase (see Fig. 3), the casein kinase II reaction was terminated by heating at $100^{\circ} \mathrm{C}$ for $5 \mathrm{~min}$ or, if phenyl-Sepharose chromatography was performed (see below), quick-freezing in solid $\mathrm{CO}_{2}$ /ethanol. Both these methods permanently inactivate casein kinase II. Phosphorylation reactions with the insulin-receptor kinase were performed as published, with partially purified receptors from rat hepatocytes [6] or highly purified human placental insulin receptors [7].

SDS/PAGE in $10 \%$ - or $15 \%$-polyacrylamide gels and autoradiography were performed as previously described [6]. The amount of ${ }^{32} \mathrm{P}$ incorporated into calmodulin was quantified by excising the calmodulin band from the gel, solubilizing in water/Protosol/Aquasol (1:2:10, by vol.) and counting radioactivity [6].

\section{Phenyl-Sepharose chromatography}

Calmodulin was phosphorylated by casein kinase II (as described above, except that non-radioactive ATP was used) and the reaction stopped by quick freezing in solid $\mathrm{CO}_{2}$ /ethanol. Phosphocalmodulin was separated from the other reagents by phenyl-Sepharose chromatography by a modification of a described method [23]. Briefly, $1 \mathrm{ml}$ of phenyl-Sepharose was preequilibrated with $5 \mathrm{~mm}-\mathrm{CaCl}_{2}$ and $1.5 \mathrm{M}-\mathrm{NaCl}$ in $50 \mathrm{~mm}$ Tris/ $\mathrm{HCl}$ ( $\mathrm{pH}$ 7.4) (buffer $\mathrm{B}$ ). The $\mathrm{Ca}^{2+}$ concentration of the sample was adjusted to $2 \mathrm{~mm}$ immediately before application to the column. The column was washed extensively with buffer $\mathbf{B}$, followed by $5 \mathrm{ml}$ of $5 \mathrm{~mm}-\mathrm{CaCl}_{2}$ in $50 \mathrm{~mm}-\mathrm{Tris} / \mathrm{HCl}(\mathrm{pH} \mathrm{7.4})$ (buffer $\mathrm{C}$ ) to remove the $\mathrm{NaCl}$. Calmodulin was eluted from the column with modified buffer $\mathrm{C}$ (the $\mathrm{CaCl}_{2}$ is replaced by $10 \mathrm{~mm}$ EGTA). The buffer was removed by Sephadex G-25 gel-filtration chromatography, with water as the solvent, and the sample was concentrated.

\section{Separation of tryptic peptides}

To determine the specific amino acid residues phosphorylated, ${ }^{32}$ P-labelled phosphocalmodulin was isolated by phenylSepharose chromatography as described above. Tryptic digestion was performed for $4 \mathrm{~h}$ at $37^{\circ} \mathrm{C}$ in $1 \mathrm{~mm}$-EGTA containing $0.1 \mathrm{M}$ $\mathrm{NH}_{4} \mathrm{HCO}_{3}$ and $40 \mu \mathrm{g}$ of trypsin $/ \mathrm{ml}$. The peptides were separated by a $\mathrm{RPC}_{4}$ Vydac column with a linear gradient from $0-60 \% \mathrm{~B}$ over $90 \mathrm{~min}$ at $1 \mathrm{ml} / \mathrm{min}$ (solvent $A$ was $0.1 \%$ trifluoroacetic acid in water; solvent B was $0.095 \%$ trifluoroacetic acid in $90 \%$ acetonitrile). Peptide elution was monitored by the $A_{214}$, fractions were collected and radioactivity of samples was determined. Some $22 A_{214}$ peaks were eluted, but only four contained significant radioactivity. The fractions for each radiolabelled peptide were divided into two equal portions and dried. One was used for phosphoamino acid analysis, and the other for determining the amino acid composition.

\section{Sequencing of tryptic phosphopeptides}

To determine amino acid composition, the phosphorylated peptides were hydrolysed with gaseous $6 \mathrm{M}-\mathrm{HCl} / 1 \%$ phenol for $1 \mathrm{~h}$ at $150^{\circ} \mathrm{C}$. Amino acids were separated and quantified on a Brownlee $\mathrm{C}_{18}$-PTC h.p.l.c. column as previously described [24]. The amino acids from each peptide were matched exactly with known tryptic fragments by using the amino acid sequence of calmodulin [25]. Phosphoamino acid analysis was performed by hydrolysing the tryptic fragments for both 1 and $4 \mathrm{~h}$ with gaseous $6 \mathrm{M}-\mathrm{HCl} / 1 \%$ phenol at $110^{\circ} \mathrm{C}$ to ensure complete hydrolysis without significant loss of phosphate. A Vydac oligonucleotide h.p.l.c. column was used as previously described [26] for complete separation of phosphoserine, phosphothreonine, phosphotyrosine and $\mathrm{P}_{1}$. The longer hydrolysis time resulted in a slight decrease in total phosphoamino acids and an increase in free $P_{i}$, but no alteration in the sites of phosphorylation (results not shown). Each ${ }^{32} \mathrm{P}$ peak contained only one phosphopeptide.

\section{Other methods}

Phosphorylation of poly $\left(\mathrm{Glu}_{4}, \mathrm{Tyr}_{1}\right)$ was determined essentially as described by Sahal \& Fujita-Yamaguchi [27]. Free $\mathrm{Ca}^{2+}$ concentration was measured with an Orion $\mathrm{Ca}^{2+}$ electrode 93-20, reference 90-01, and microprocessor $\mathrm{pH} /$ millivoltmeter 811 [28]. Protein content was determined by the method of Lowry et al. [29] or Bradford [30] with BSA as standard. Phosphoamino acid analysis was performed by h.p.l.c. as described [6] or by thinlayer electrophoresis in formic acid/acetic acid/water (25:78:897, by vol.) at $600 \mathrm{~V}$ for $7 \mathrm{~h}$.

\section{RESULTS AND DISCUSSION}

\section{Insulin stimulates the phosphorylation of calmodulin in intact rat} hepatocytes

Insulin increases calmodulin phosphorylation in hepatocytes on average approx. 3-fold (Fig. 1). The phosphoprotein was identified as calmodulin by immunoblotting (Fig. $1 a$, lanes 3 and 4) with a new highly specific anti-calmodulin monoclonal antibody that was heretofore unavailable [20]. This phosphoprotein is completely removed by immunoprecipitation with the anticalmodulin monoclonal antibody (results not shown). Furthermore, immunoprecipitation with this antibody confirms both its identification as calmodulin (Fig. $1 a$, lanes 5 and 6) and the insulin-sensitivity (Fig. 1b). By immunoprecipitation, insulin was shown to enhance calmodulin phosphorylation $3.2 \pm 0.7$-fold (mean \pm S.E.M., $n=5$ ). Probing the immunoblot with an anti- 
(a)

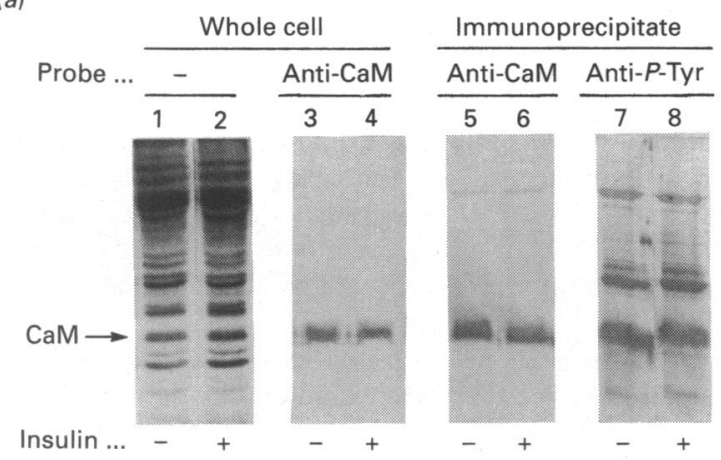

(b)

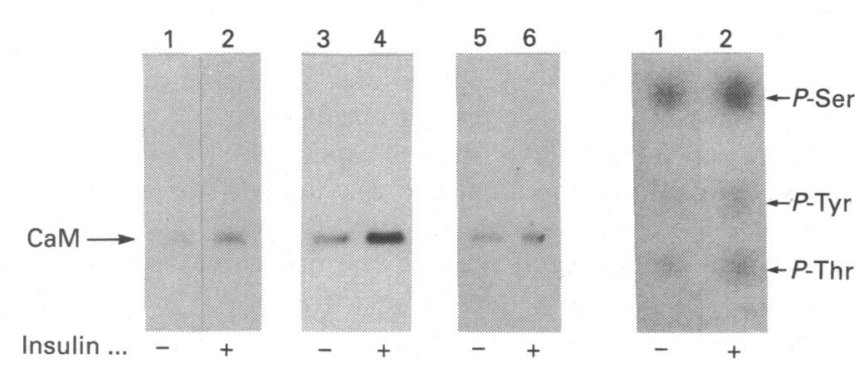

Fig. 1. Insulin-stimulated phosphorylation of calmodulin in hepatocytes

Isolated rat hepatocytes loaded with $\left[{ }^{32} \mathrm{P}\right] \mathrm{P}_{\mathrm{i}}$ were incubated in the presence $(+)$ or absence $(-)$ of $67 \mathrm{~nm}$-insulin and processed as described in the Experimental section. (a) Reactions were stopped with $10 \%$ trichloroacetic acid and proteins separated by SDS/PAGE. After transfer to poly(vinylidene difluoride), autoradiography was performed (lanes 1 and 2) and the blot was probed with a specific anti-calmodulin monoclonal antibody (lanes 3 and 4). Cell lysates were precipitated with the anti-calmodulin monoclonal antibody, processed by SDS/PAGE and immunoblots were probed with the anti-calmodulin monoclonal antibody (lanes 5 and 6) or anti-phosphotyrosine antibody (lanes 7 and 8). Representative experiments are shown. (b) Cell lysates precipitated with anti-calmodulin antibody were processed by SDS/PAGE, transfer to poly(vinylidene difluoride) and autoradiography. Three independent experiments are shown. The position of migration of calmodulin (CaM) is designated. (c) Hepatocytes incubated with $(+)$ or without $(-)$ insulin were immunoprecipitated with the anticalmodulin monoclonal antibody and samples were separated by SDS/PAGE. After transfer to poly(vinylidene difluoride), calmodulin was hydrolysed with $6 \mathrm{M}-\mathrm{HCl}$ at $110^{\circ} \mathrm{C}$ for $2 \mathrm{~h}$ and phosphoamino acids were separated by thin-layer electrophoresis. The positions of migration of phosphothreonine ( $P$-Thr), phosphotyrosine $(P$-Tyr) and phosphoserine $(P$-Ser $)$ are designated. PAA, phosphoamino acid analysis.

phosphotyrosine antibody (Fig. $1 a$, lanes 7 and 8) demonstrates that calmodulin is phosphorylated on tyrosine residues. By this method insulin does not appear to increase phosphate incorporation significantly at this site. Phosphoamino acid analysis of immunoprecipitated phosphocalmodulin indicates that calmodulin is constitutively phosphorylated and insulin increases phosphate incorporation into serine, threonine and tyrosine residues (Fig. 1c). In addition to calmodulin, the heavy and light chains of the immunoprecipitating antibody are visible above calmodulin in Fig. 1(b), lanes 5-8. Using this same anticalmodulin monoclonal antibody for immunoprecipitation, we have observed that insulin stimulates calmodulin phosphorylation in BC3H-1 myocytes (J. M. McDonald \& M. A. Moore, unpublished work).
There is an apparent discrepancy between the data obtained with the anti-phosphotyrosine antibody, which fails to demonstrate stimulation of tyrosine phosphorylation of calmodulin by insulin (Fig. 1a, lanes 7 and 8), and the data obtained by phosphoamino acid analysis of ${ }^{32} \mathrm{P}$-labelled calmodulin (Fig. 1c), which shows that insulin stimulates the phosphorylation of calmodulin on tyrosine as well as serine and threonine residues. Note, however, in the basal state there is little ${ }^{32} \mathrm{P}$ incorporated on tyrosine resides. We have observed in immunoblots of calmodulin phosphorylated in vitro on Tyr-99 that the intensity of immunostaining with anti-phosphotyrosine antibody is directly proportional to the quantity of phosphocalmodulin. The broad bands seen by immunostaining with the anti-calmodulin and anti-phosphotyrosine antibodies (Fig. 1a, lanes 5-8) compared with the narrow bands on the autoradiogram of immunoprecipitated calmodulin (Fig. $1 b$ ) are consistent with the existence of multiple pools of calmodulin. This suggests that a major component of calmodulin has a slow rate of turnover of phosphate on tyrosine residues, preventing complete equilibration with ${ }^{32} \mathrm{P}$. Since insulin increases tyrosine phosphorylation, this stimulation possibly occurs in a different pool of calmodulin, resulting in an increase in ${ }^{32} \mathrm{P}$-labelled tyrosine without an increase in total phosphotyrosine in the molecule. The rapidly turningover pool is possibly in a subcellular compartment, perhaps located in the plasma membrane or nucleus. Studies are needed to determine the stoichiometry of calmodulin phosphorylation in both the stable and rapidly changing pools.

The lack of significant phosphorylation of calmodulin in intact cells reported by Blackshear \& Haupt [11] contradicts both our findings and those of three other groups $[3,4,9]$, who identified phosphocalmodulin in intact cells and tissues including brain, muscle and fibroblasts. Four important methodological details distinguish the present studies from earlier ones that did not detect phosphocalmodulin. These details underscore the lack of interpretability of negative data unless appropriate internal standards are employed. First, the method for terminating the reaction has proved critical. In the studies presented here, the reaction was terminated with $10 \%$ trichloroacetic acid or boiling SDS. This appears to be a key step in detecting phosphocalmodulin in intact cells, and was successfully employed in identification of phosphocalmodulin in intact cells by others. This technique probably succeeds owing to the rapid inactivation of phosphatase activity, since other investigators have demonstrated the inability to detect certain intracellular phosphotyrosyl-proteins with routinely used phosphatase inhibitors [31,32]. Second, the ability of our monoclonal antibody to immunoprecipitate calmodulin [20] has provided convincing data where earlier immunoprecipitation attempts did not. Using the polyclonal antibody (No. 465, provided by Linda Van Eldik, Vanderbilt University) which was unsuccessful in the immunoprecipitation studies of Blackshear \& Haupt [11], we immunoprecipitated less than $3 \%$ of calmodulin phosphorylated in vitro on Tyr-99 (compared with $98 \%$ immunoprecipitated with our monoclonal antibody; results not shown). Third, anti-phosphotyrosine antibodies cannot be used for immunoprecipitation studies with calmodulin because they generally do not immunoprecipitate phosphotyrosyl-proteins of less than $30 \mathrm{kDa}$ [33]. Fourth, in contrast with the negative studies mentioned above, we have utilized specific transfer conditions and fixation methods designed to detect calmodulin by immunoblotting [21].

\section{Phosphorylation of calmodulin by casein kinase II and the insulin receptor}

Calmodulin is phosphorylated in vitro on Tyr-99 by the insulinreceptor kinase [34], and on serine and threonine residues by 


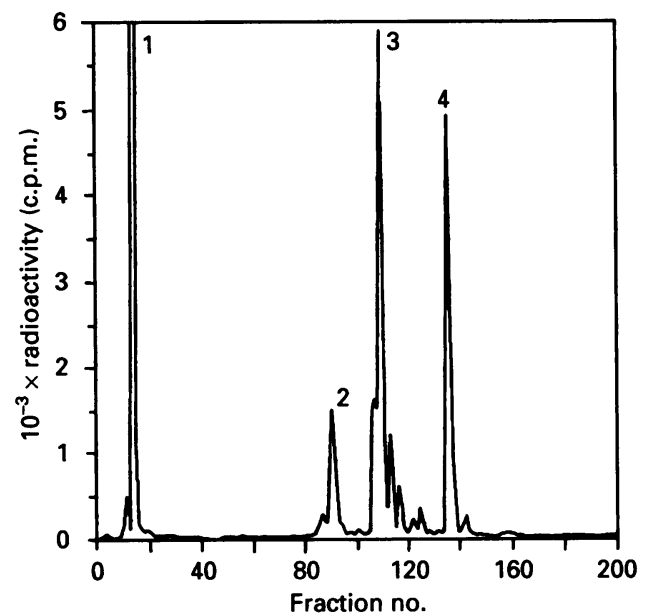

Fig. 2. Separation of ${ }^{32} \mathbf{P}$-labelled tryptic peptides of calmodulin

Tryptic peptides derived from calmodulin phosphorylated by casein kinase II were separated by reverse-phase h.p.l.c. as described in the Experimental section. Flow rate was $1 \mathrm{ml} / \mathrm{min}$, and $330 \mu \mathrm{l}$ fractions were collected. Radioactivity was measured in a $10 \mu \mathrm{l}$ portion of each fraction by liquid-scintillation spectrometry.

casein kinase II [8]. Because insulin increases casein kinase II activity $[14,15]$ and stimulates calmodulin phosphorylation in hepatocytes on serine and threonine residues, in addition to tyrosine (see Fig. 1), we hypothesized that the phosphorylation of calmodulin by casein kinase II and the insulin-receptor kinase possibly represents an important point of cross-talk between the two signalling pathways. The sites of calmodulin phosphorylated by casein kinase II were therefore determined.

Calmodulin phosphorylated by casein kinase II was digested by trypsin and the peptides were separated by reverse-phase h.p.l.c. This produced four radioactive peaks (Fig. 2). The amino acid sequence of each peak was determined and is shown in Table 1. These peptide sequences all correspond to known sequences in calmodulin. Since peptides 1-3 contain only one serine or one serine and one threonine, assignment of the exact phosphoamino acid was straightforward. Since peak 4 contains two threonine residues, standard Edman degradation as described by Crimmins et al. [24] was performed to pinpoint the exact site of phosphorylation. Thr-110 gave the expected signal in the cycling, whereas Thr-117 was absent, suggesting that the latter had been post-translationally modified and was not eluted from the glass-fibre filter. All phosphorylation sites detected are characteristic casein kinase II consensus sequences. The relative amount of phosphorylation at each site is expressed as a percentage of the total ${ }^{32} \mathrm{P}$ incorporated into the radiolabelled peptides (Table 1).

Analysis of interactions between multiple kinases are difficult to investigate in vivo. We therefore examined this in a system in vitro by sequentially phosphorylating calmodulin, initially by casein kinase II and then by the insulin receptor. Phosphorylation of calmodulin by the insulin-receptor kinase is altered when calmodulin is first phosphorylated by casein kinase II. As demonstrated in Fig. 3(a), the insulin receptor stimulates the phosphorylation of calmodulin that has been pre-phosphorylated with unlabelled ATP on serine and threonine residues by casein kinase II to a much greater extent (lane 2; 3.0 \pm 0.5 -fold, $n=4)$ than it stimulates the phosphorylation of non-prephosphorylated calmodulin (lane 1). Heating the sample for 5 min at $100^{\circ} \mathrm{C}$ before adding $\left[\gamma_{-32}{ }^{32} \mathrm{P}\right] \mathrm{ATP}$, insulin and the insulin receptor completely inactivates the casein kinase II (Fig. $3 a$, lane 3 ), ensuring that there is no active casein kinase II present in the insulin-receptor phosphorylation assay. Lane 4 represents a positive control illustrating that casein kinase II itself phosphorylates calmodulin during the preincubation.

The stoichiometries of phosphorylation of calmodulin presented in Fig. 3(a) are as follows: $0.03,0.13$ and $0.25 \mathrm{~mol}$ of phosphate/mol of calmodulin for insulin receptor only (lane 1 ), insulin-stimulated phosphorylation of calmodulin prephosphorylated by casein kinase II (lane 2) and casein kinase II only (lane 4) respectively. The stoichiometry of calmodulin phosphorylation by the insulin receptor alone (lane 1) is at the level that we routinely observe under standard phosphorylation conditions [6]. Studies are needed to determine whether the stoichiometry of pre-phosphorylation by casein kinase II modifies the amplification or site of subsequent insulin-stimulated phosphorylation.

To ensure that there are no other factors in the casein kinase II assay which may alter the insulin-receptor kinase assay,

Table 1. (a) Amino acid sequence of the tryptic peptides from calmodulin phosphorylated by casein kinase II, and (b) sites of phosphorylation

Peptide numbers correspond to the peaks in Fig. 2. In the sequences, phosphorylated amino acids are indicated by bold letters. Values in (a) for 'Relative phosphorylation' are the amounts of ${ }^{32} \mathrm{P}$ incorporated into each peptide, expressed as a percentage of the total radioactivity incorporated into calmodulin.

\begin{tabular}{|c|c|c|c|}
\hline \multirow[b]{2}{*}{ (a) Peptide } & \multirow[b]{2}{*}{ Amino acid sequence } & \multicolumn{2}{|c|}{$\begin{array}{c}\text { Relative } \\
\text { phosphorylation }\end{array}$} \\
\hline & & Ser & Thr \\
\hline 1 & $M^{78}-K-D-T^{79}-D-S^{81}$-E-E-E-I-R-E-A-F-R ${ }^{90}$ & 50 & 14 \\
\hline 2 & $D^{95}-G-N-G-Y-I-S^{101}-A-A-E-L-R^{106}$ & 5 & 0 \\
\hline 3 & V $^{91}$-F-D-K-D-G-N-G-Y-I-S ${ }^{101}-A-A-E-L-R^{106}$ & 20 & $\mathbf{0}$ \\
\hline 4 & $\mathrm{H}^{107}$-V-M-T-N-L-G-E-K-L-T ${ }^{117}$-D-E-E-V-D-E-M-I-R ${ }^{126}$ & 0 & 11 \\
\hline
\end{tabular}

\begin{tabular}{lcccc}
\hline (b) Site of phosphorylation $\ldots$ & $\operatorname{Thr}^{79}$ & $\operatorname{Ser}^{81}$ & $\operatorname{Ser}^{101}$ & $\operatorname{Thr}^{117}$ \\
\hline $\begin{array}{l}\text { Relative phosphorylation } \\
(\%) \ldots\end{array}$ & 14 & 50 & 25 & 11
\end{tabular}




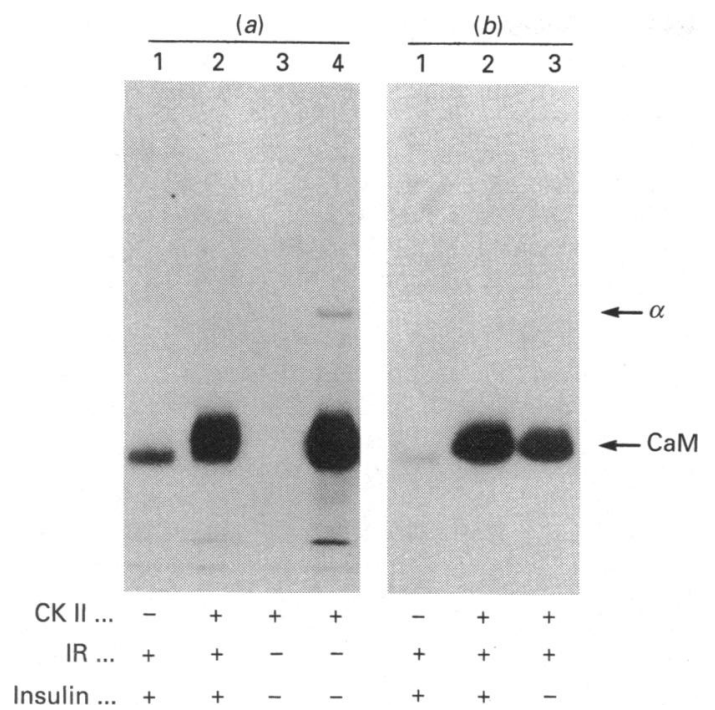

Fig. 3. Effect of phosphorylation of calmodulin by casein kinase II on subsequent phosphorylation by the insulin receptor

(a) Phosphorylation reactions were performed as described in the Experimental section. The sample in lane 1 was phosphorylated by partially purified hepatocyte insulin-receptor kinase (IR) only. Samples in lanes 2 and 3 were initially phosphorylated by casein kinase II (CK II) with non-radioactive ATP only (no $\left[\gamma-{ }^{32} \mathrm{P}\right] \mathrm{ATP}$ present) and the assay was stopped by heating at $100^{\circ} \mathrm{C}$ for $5 \mathrm{~min}$. Then the sample in lane 2 was phosphorylated by the insulin receptor in the presence of $\left[\gamma_{-}{ }^{32} \mathrm{P}\right] \mathrm{ATP}$, and that in lane 3 was incubated with $\left[\gamma_{-}{ }^{32} \mathrm{P}\right] A T P$ only. Incubation times were $30 \mathrm{~min}$ for the casein kinase II assay and $60 \mathrm{~min}$ for the insulin receptor assay. Lane 4 is a control (casein kinase II with $\left[\gamma^{32}\right.$ P $]$ ATP for $30 \mathrm{~min}$ only). Insulin (67 nM) was present in lanes 1 and 2. (b) Calmodulin was phosphorylated by casein kinase II (CK II) as described for (a) in the presence of non-radioactive ATP and the reaction was stopped by quick freezing in solid $\mathrm{CO}_{2} /$ ethanol. The phosphorylated calmodulin was then separated from the reaction mixture by phenylSepharose chromatography as described in the Experimental section. The second incubation was performed with the insulin receptor in the presence $(+)$ or absence $(-)$ of $67 \mathrm{nM}$-insulin. Lane 1 contains calmodulin that was not pre-phosphorylated by casein kinase II and was phosphorylated by the insulin-receptor kinase only. Representative autoradiograms are illustrated, with the positions of migration of calmodulin (CaM) and the $\alpha$ subunit of casein kinase II $(\alpha)$ designated.

calmodulin phosphorylated by casein kinase II was separated by phenyl-Sepharose chromatography before phosphorylation by the insulin-receptor kinase (Fig. 3b). Pre-phosphorylation of calmodulin by casein kinase II increases subsequent insulinstimulated phosphorylation approx. 35-fold (compare lanes 1 and 2, Fig. 3b). To confirm that this phosphorylation is via an insulin-stimulated kinase, we performed the assay in the presence (lane 2) and absence (lane 3) of insulin. In the experiment shown, insulin stimulates ${ }^{32} \mathrm{P}$ incorporation into pre-phosphorylated calmodulin approx. 2-fold. In other experiments insulin stimulation ranged from 2- to 8-fold.

Phosphoamino acid analysis of calmodulin phosphorylated initially by casein kinase II (in the absence of insulin) and then by the insulin receptor (in the presence of insulin) provided surprising results. The insulin-stimulated kinase phosphorylates calmodulin exclusively on serine and threonine residues (Fig. 4). No tyrosine phosphorylation is present. Since these findings were so unexpected, phosphoamino acid analysis of this calmodulin was performed independently in two different laboratories by different techniques, h.p.l.c. (Fig. 4) or t.l.c. (results not shown). Both methods give the same results, showing phosphorylation

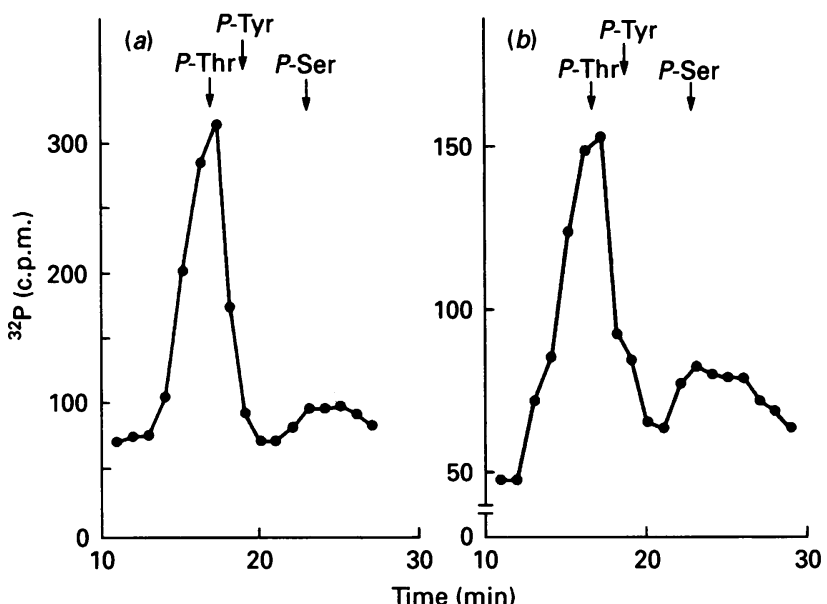

Fig. 4. Phosphoamino acid analysis of calmodulin phosphorylated by casein kinase II and the insulin receptor

Phosphorylation reactions were performed as described in the Experimental section. Phosphorylation by casein kinase II was performed in the presence of non-radioactive ATP (no $\left[\gamma{ }^{32} \mathrm{P}\right] \mathrm{ATP}$ present) and stopped by heating at $100^{\circ} \mathrm{C}$ for $5 \mathrm{~min}$. The samples were then phosphorylated by addition of the insulin receptor in the presence of $67 \mathrm{nM}$-insulin and $\left[\gamma_{-}{ }^{32} \mathrm{P}\right] \mathrm{ATP}$. Highly purified human placental insulin receptors $(a)$ and partially purified rat liver insulin receptors $(b)$ were used in the second incubation. Phosphoamino acid analysis was performed by h.p.l.c. as described in the Experimental section. The retention times for phosphothreonine $(P$-Thr), phosphotyrosine $(P$-Tyr) and phosphoserine ( $P$-Ser) were determined by simultaneous u.v. detection of internal phosphorylated standards.

exclusively on threonine and serine residues. Virtually identical results are obtained when calmodulin pre-phosphorylated by casein kinase II is phosphorylated by a highly purified insulin receptor preparation from human placenta (Fig. $4 a$ ) or partially purified rat hepatocyte insulin receptors (Fig. $4 b$ ). Repetition of this experiment five times with partially purified hepatocyte insulin receptors resulted in variable amounts of threonine and serine phosphorylation, but no tyrosine phosphorylation.

The activity of the insulin-receptor tyrosine kinase, measured with the synthetic substrate poly $\left(\mathrm{Glu}_{4}, \mathrm{Tyr}_{1}\right)$, is unchanged in the presence of calmodulin pre-phosphorylated by casein kinase II (results not shown). Caution should be used in interpreting this last observation, however, because $\operatorname{poly}\left(\mathrm{Glu}_{4}, \mathrm{Tyr}_{1}\right)$ has been shown to inhibit some serine/threonine kinases [35]. It is not known why phosphorylation on serine/threonine residues prevents subsequent tyrosine phosphorylation of calmodulin by the insulin-receptor kinase. Among the possible explanations are: (1) a phospho-seryl/-threonyl phosphatase is converted into a phosphotyrosyl phosphatase [36]; (2) phosphocalmodulin activates a phosphotyrosyl phosphatase [37]; (3) a serine/ threonine kinase associated with the insulin receptor [38] is activated by phosphocalmodulin and phosphorylates calmodulin, preventing tyrosine phosphorylation; (4) phosphorylation of calmodulin by casein kinase II alters its tertiary conformation, which inhibits phosphorylation on tyrosine but permits that on serine/threonine; it is possible that phosphate incorporation on to Ser-101 produces steric hindrance of phosphorylation of Tyr-99; and (5) the phosphorylation of calmodulin on serine/threonine residues effects its interaction with the insulin receptor, resulting in the kinase specificity changing from tyrosine to serine/threonine. Recently enzymes have been identified in three different cell types that are related in sequence to serine/threonine kinases, but exhibit serine-, 
threonine- and tyrosine-phosphorylating activity [39-41]. This demonstrates the existence of kinases that can phosphorylate all hydroxy amino acids. Changing the tertiary structure and charge of calmodulin by phosphorylation may produce an alternative recognition site for the kinase, altering its specificity.

Most phosphorylated proteins are modified by at least two protein kinases [12]. Calmodulin phosphorylated on serine/threonine ([3,4,9]; the present work; J. A. Traugh, personal communication) and tyrosine $([9,10]$; the present work) residues occurs in intact cells. Importantly, in 3T3-L1 cells one of the phosphorylated forms is identical with a phosphopeptide produced by phosphorylation of calmodulin in vitro by casein kinase II (J. A. Traugh, personal communication). Furthermore, Fukami et al. [9] demonstrated that calmodulin is phosphorylated on serine/threonine residues in normal and Rous-sarcoma-virustransformed cells. In contrast, calmodulin is also phosphorylated on tyrosine residues in the transformed cells only [9].

Phosphorylation of calmodulin by casein kinase II may provide a species of calmodulin which can be rapidly modified in response to insulin, producing significant metabolic sequelae. Calmodulin phosphorylated in vitro on Tyr-99 by the insulin-receptor kinase has an enhanced ability to activate cyclic GMP phosphodiesterase (J. P. Williams, H. Jo \& J. M. McDonald, unpublished work), whereas calmodulin phosphorylated on serine/threonine residues has diminished activity [42]. This, coupled with the presence of phosphocalmodulin in intact cells, suggests that phosphorylation of calmodulin on tyrosine and serine/threonine residues may provide important post-translational regulatory mechanisms for modulating intracellular calmodulin-regulated events. Specifically, the phosphorylation of calmodulin by both casein kinase II and the insulin-receptor kinase may represent a point where two kinases intercommunicate, producing signal amplification and modulation in the intracellular transduction of the insulin signal.

We thank E. Sheehan, R. D. Gale, S. Byer, and R. S. Thoma for their excellent technical assistance, D. Strahs and Dr. J. Crawford for isolating the hepatocytes, Dr. J. Traugh of the University of California, Riverside, for donating casein kinase II, Eli Lilly Co. (Indianapolis, IN, U.S.A.) for the gift of insulin, and M. Rosado and C. Yalden for preparing the manuscript. This work was supported in part by Research Grants DK01680 (D. B. S.) and DK25897 (J.M. M.) from the National Institutes of Health and the American Cancer Society (J.M.M.).

\section{REFERENCES}

1. Cheung, W. Y. (1980) Science 207, 19-27

2. Klee, C. B., Crouch, T. H. \& Richman, P. G. (1980) Annu. Rev. Biochem. 49, 489-515

3. Plancke, Y. D. \& Lazarides, E. (1983) Mol. Cell. Biol. 3, 1412-1420

4. Nakajo, S., Hayashi, K., Daimatsu, T., Tanaka, M., Nakaya, K. \& Nakamura, Y. (1986) Biochem. Int. 13, 687-693

5. Graves, C. B., Gale, R. D., Laurino, J. P. \& McDonald, J. M. (1986) J. Biol. Chem. 261, 10429-10438

6. Sacks, D. B. \& McDonald, J. M. (1988) J. Biol. Chem. 263, 2377-2383

Received 17 September 1991/17 February 1992; accepted 6 March 1992
7. Sacks, D. B., Fujita-Yamaguchi, Y., Gale, R. D. \& McDonald, J. M. (1989) Biochem. J. 263, 803-812

8. Meggio, F., Brunati, A. M. \& Pinna, L. A. (1987) FEBS Lett. 215, 241-246

9. Fukami, Y., Nakamura, T., Nakayama, A. \& Kanehisa, T. (1986) Proc. Natl. Acad. Sci. U.S.A. 83, 4190-4193

10. Colca, J. R., DeWald, D. B., Pearson, J. D., Palazuk, B. J., Laurino, J. P. \& McDonald, J. M. (1987) J. Biol. Chem. 262, 11399-11402

11. Blackshear, P. J. \& Haupt, D. M. (1989) J. Biol. Chem. 264, 3854-3858

12. Tuazon, P. T. \& Traugh, J. A. (1991) in Advances in Second Messenger and Phosphoprotein Research (Greengard, P. \& Robison, G. A., eds.), vol. 23, pp. 123-164, Raven Press, New York

13. De Paoli-Roach, A. A. (1984) J. Biol. Chem. 259, 12144-12152

14. Sommercorn, J., Mulligan, J. A., Lozeman, F. J. \& Krebs, E. G. (1987) Proc. Natl. Acad. Sci. U.S.A. 84, 8834-8838

15. Klarlund, J. K. \& Czech, M. P. (1988) J. Biol. Chem. 263, 15872-15875

16. Haystead, T. A. J., Campbell, D. G. \& Hardie, D. G. (1988) Eur. J. Biochem. 175, 347-354

17. Grande, J., Perez, M. \& Itarte, E. (1988) FEBS Lett. 232, 130-134

18. Graf, J., Gautam, A. \& Boyer, J. L. (1984) Proc. Natl. Acad. Sci. U.S.A. 81, 6516-6520

19. Berry, M. N. \& Friend, D. S. (1969) J. Cell Biol. 43, 506-520

20. Sacks, D. B., Porter, S. E., Ladenson, J. H. \& McDonald, J. M. (1991) Anal. Biochem. 194, 369-377

21. Van Eldik, L. J. \& Wolchok, S. R. (1984) Biochem. Biophys. Res. Commun. 124, 752-759

22. Hathaway, G. M. \& Traugh, J. A. (1983) Methods Enzymol. 99, 317-331

23. Gopalakrishna, R. \& Anderson, W. B. (1982) Biochem. Biophys. Res. Commun. 104, 830-836

24. Crimmins, D. L., Thoma, R. S., McCourt, D. W. \& Schwartz, B. D. (1989) Anal. Biochem. 176, 255-260

25. Babu, Y. S., Sack, J. S., Greenhough, T. J., Bugg, C. E., Means, A. R. \& Cook, W. J. (1985) Nature (London) 315, 37-40

26. McCroskey, M. C., Colca, J. R. \& Pearson, J. D. (1988) J. Chromatogr. 442, 307-315

27. Sahal, D. \& Fujita-Yamaguchi, Y. (1987) Anal. Biochem. 167, 23-30

28. Kotagal, N., Colca, J. R. \& McDaniel, M. L. (1983) J. Biol. Chem. 258, 4808-4813

29. Lowry, O. H., Rosebrough, N. J., Farr, A. L. \& Randall, R. J. (1951) J. Biol. Chem. 193, 265-275

30. Bradford, M. M. (1976) Anal. Biochem. 72, 248-254

31. Kamps, M. P. \& Sefton, B. M. (1988) Oncogene 2, 305-315

32. Rothenberg, P. L., Lane, W. S., Karasik, A., Backer, J., White, M. \& Kahn, C. R. (1991) J. Biol. Chem. 266, 8302-8311

33. Levenson, R. M. \& Blackshear, P. J. (1989) J. Biol. Chem. 264 19984-19993

34. Laurino, J. P., Colca, J. R., Pearson, J. D., DeWald, D. B. \& McDonald, J. M. (1988) Arch. Biochem. Biophys. 265, 8-21

35. Tellez, R., Gatica, M., Allende, C. C. \& Allende, J. E. (1990) FEBS Lett. 265, 113-116

36. Goris, J., Pallen, C. J., Parker, P. J., Hermann, J., Waterfield, M. D. \& Merlevede, W. (1988) Biochem. J. 256, 1029-1034

37. King, M. J. \& Sale, G. J. (1988) Biochem. J. 256, 893-902

38. Czech, M. P., Klarlund, J. K., Yagaloff, K. A., Bradford, A. P. \& Lewis, R. E. (1988) J. Biol. Chem. 263, 11017-11020

39. Howell, B. W., Afar, D. E., Lew, J., Douville, E. M., Icely, P. L., Gray, D. A. \& Bell, J. C. (1991) Mol. Cell. Biol. 11, 568-572

40. Ben-David, Y., Letwin, K., Tannock, L., Bernstein, A. \& Pawson, T. (1991) EMBO J. 10, 317-325

41. Featherstone, C. \& Russell, P. (1991) Nature (London) 349, 808-811

42. Sacks, D. B., Davis, H. W., Williams, J. P., Sheehan, E. L., Garcia, J. G. N. \& McDonald, J. M. (1992) Biochem. J. 283, 21-24 